6. Sohan K, Cyrus CA. Ultrasonographic observations of the fetal brain in the first 100 pregnant women with Zika virus infection in Trinidad and Tobago. Int J Gynaecol Obstet. 2017;139:278-83. http://dx.doi.org/10.1002/ijgo.12313

7. Parra-Saavedra M, Reefhuis J, Piraquive JP, Gilboa SM, Badell ML, Moore CA, et al. Serial head and brain imaging of 17 fetuses with confirmed Zika virus infection in Colombia, South America. Obstet Gynecol. 2017;130:207-12. http://dx.doi.org/10.1097/AOG.0000000000002105

8. Kleber de Oliveira W, Cortez-Escalante J, De Oliveira WT, do Carmo GM, Henriques CM, Coelho GE, et al. Increase in reported prevalence of microcephaly in infants born to women living in areas with confirmed Zika virus transmission during the first trimester of pregnancy-Brazil, 2015. MMWR Morb Mortal Wkly Rep. 2016;65:242-7. http://dx.doi.org/10.15585/ mmwr.mm6509e2

9. Cuevas EL, Tong VT, Rozo N, Valencia D, Pacheco O, Gilboa SM, et al. Preliminary report of microcephaly potentially associated with Zika virus infection during pregnancy - Colombia, JanuaryNovember 2016. MMWR Morb Mortal Wkly Rep. 2016;65:140913. http://dx.doi.org/10.15585/mmwr.mm6549e1

10. Reynolds MR, Jones AM, Petersen EE, Lee EH, Rice ME, Bingham A, et al.; U.S. Zika Pregnancy Registry Collaboration. Vital Signs: Update on Zika virus-associated birth defects and evaluation of all U.S. infants with congenital Zika virus exposureU.S. Zika Pregnancy Registry, 2016. MMWR Morb Mortal Wkly Rep. 2017;66:366-73. http://dx.doi.org/10.15585/ mmwr.mm6613e1

Address for correspondence: Intawat Nookaew, Department of Biomedical Informatics and Department of Physiology and Biophysics, College of Medicine, University of Arkansas for Medical Sciences, Little Rock, AR 72205, USA; email: inookaew@uams.edu; Navin Horthongkham, Department of Microbiology, Faculty of Medicine, Siriraj Hospital, Mahidol University, Wanglang Road, Bangkoknoi Bangkok, 10700 Thailand; email: navin.hor@mahidol.ac.th

\section{Dirofilaria repens Nematode Infection with Microfilaremia in Traveler Returning to Belgium from Senegal}

\author{
Idzi Potters, Gaëlle Vanfraechem, \\ Emmanuel Bottieau
}

Author affiliations: Institute of Tropical Medicine Antwerp, Antwerp, Belgium (I. Potters, E. Bottieau); Centre Hospitalier Interrégional Edith Cavell Hospital Group, Brussels, Belgium (G. Vanfraechem)

DOI: https://doi.org/10.3201/eid2409.180462
We report human infection with a Dirofilaria repens nematode likely acquired in Senegal. An adult worm was extracted from the right conjunctiva of the case-patient, and blood microfilariae were detected, which led to an initial misdiagnosis of loiasis. We also observed the complete life cycle of a $D$. repens nematode in this patient.

$\mathrm{O}$ n October 14, 2016, a 76-year-old man from Belgium was referred to the travel clinic at the Institute of Tropical Medicine (Antwerp, Belgium) because of suspected loiasis after a worm had been extracted from his right conjunctiva in another hospital. Apart from stable, treated arterial hypertension and non-insulin-dependent diabetes, he had no remarkable medical history. For the past 10 years, the patient spent several months per year in a small beach house in Casamance, Senegal, and did not travel to any other destination outside Belgium. His last stay in Senegal was during October 2015-May 2016, during which time he took care of dogs roaming on the beach.

On September 30, 2016, unilateral right conjunctivitis developed in the patient, and he was referred to an ophthalmologist, who extracted a worm (length $10 \mathrm{~cm}$, diameter $470 \mu \mathrm{m})$ (Figure, panel A). The patient did not report any previous symptoms such as itching, larva migrans, or migratory swelling.

Results of a physical examination were unremarkable. Blood analysis showed a leukocyte count of 8,330 cells $/ \mu \mathrm{L}$ and $16.8 \%$ eosinophils. All other first-line laboratory parameters, including total level of IgE, were within reference ranges. A pan filaria IgG-detecting assay (Acanthocheilonema viteae ELISA Kit; Bordier Affinity Products SA, Crissier, Switzerland) showed a positive result. All other relevant serologic assays showed negative results. Blood smear examination after Knott concentration showed 6 microfilariae of Dirofilaria sp. $/ \mathrm{mL}$ of blood.

Although treatment for such infections is not well established, the patient was given ivermectin $(200 \mu \mathrm{g} /$ $\mathrm{kg}$, single dose) on October 15 . The patient had general itching and fever (temperature up to $40^{\circ} \mathrm{C}$ ) the next day. Blood test results on October 26 showed a leukocyte count of 8,410 cells $/ \mu \mathrm{L}$ and $27.9 \%$ eosinophils. The patient recovered uneventfully. In September 2017, the patient was free of symptoms, and his eosinophil count was 470 cells $/ \mu \mathrm{L}$.

Human dirofilariasis is a mosquitoborne zoonosis caused by filarial worms of the genus Dirofilaria, which has 2 subgenera: Dirofilaria (the most common species is D. immitis) and Nochtiella (the most common species is D. repens). The main clinical manifestations are subcutaneous or ocular nodules, and a diagnosis is usually made by biopsy or worm extraction. The risk for humans to acquire dirofilariasis has increased because of climate changes and larger distribution ranges of vectors (1). 

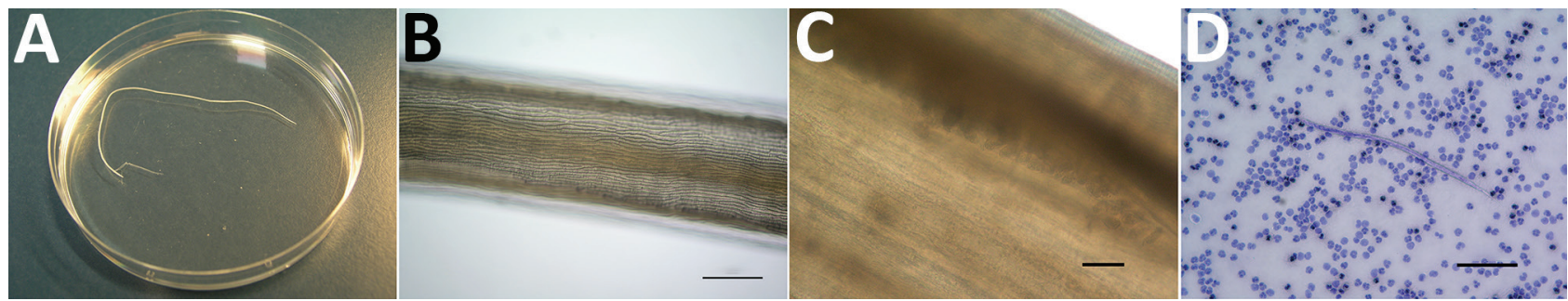

Figure. Dirofilaria repens adult worm isolated from the right conjunctiva of a 76-year-old man who returned to Belgium from Senegal, and microfilaria detected by using the Knott test. A) Macroscopic image of the adult. B) Microscopic image of the adult cuticle, showing the typical longitudinal ridges. Scale bar indicates $200 \mu \mathrm{m}$. C) Eggs in utero, indicating that the adult is a gravid female worm. Scale bar indicates $50 \mu \mathrm{m}$. Panel $\mathrm{C}$ has been cropped and contrast was increased to improve visibility of eggs. D) Microfilaria found in the blood of the patient. In a Knott test, microfilariae usually appear stretched out and slightly longer than those observed in a Giemsa-stained blood film. Scale bar indicates $100 \mu \mathrm{m}$.

Human dirofilariasis is currently considered an emerging zoonosis (2). D. repens nematodes have a large geographic distribution that includes Africa, Asia, and Europe and have recently spread into colder regions (3). Studies of primates indicate that $D$. repens nematodes need to develop for $\approx 25-34$ weeks before they are fully mature and produce microfilariae (4). This finding suggests that the patient we report acquired the infection in Senegal, possibly through close contact with dogs.

Initially, loiasis was suspected as a diagnosis, given the location of the adult worm and presence of microfilaremia. However, the length $(10 \mathrm{~cm})$ of the adult worm did not correspond to a Loa loa worm, which can reach a maximum length of $\approx 7 \mathrm{~cm}$. Microscopic examination of the cuticle identified conspicuous longitudinal ridges, which are typical for certain Dirofilaria spp. but absent in L. loa worms (Figure, panel B). These ridges also ruled out $D$. immitis worms.

When we took the largest diameter of the adult worm $(470 \mu \mathrm{m})$ into account, we made a diagnosis of $D$. repens nematode infection (5). Eggs found in utero (Figure, panel C) confirmed that the worm was a gravid adult female. This diagnosis was supported by morphologic features of the blood microfilariae: terminal extremities that did not contain nuclei (L. loa microfilariae have nuclei extending to the tip of the tail) and short cephalic spaces containing 2-4 nuclei (Figure, panel D; online Technical Appendix Figure, https://wwwnc.cdc.gov/EID/article/24/9/18-0462Techapp1.pdf). We measured 25 larvae, and they had an average length of $376 \mu \mathrm{m}$ (range 357-395 $\mu \mathrm{m}$ ) and an average diameter of $9.7 \mu \mathrm{m}$ (range $7.5-10.0 \mu \mathrm{m}$ ), all features compatible with $D$. repens microfilariae $(6,7)$.

We attempted to provide molecular confirmation of the infecting species by using 2 PCRs: 1 reported by Gioia et al. in 2010 (8) and 1 reported by Latrofa et al. in 2012 (9). Both techniques, which were performed with material from the adult worm, did not confirm identification of infecting species, probably because of prolonged preservation of the worm in formaldehyde.
D. repens worms seldom fully develop and produce microfilariae in humans. To our knowledge, 5 such cases have been reported: 3 with microfilariae in tissues surrounding adult worms and 2 with microfilariae in blood (10). There might have been immune impairment in our patient with diabetes, which enabled completion of the worm cycle, a phenomenon also observed in macaques with decreased immunity (4).

In conclusion, this case highlights the need for careful parasitologic examination when clinical and laboratory findings (i.e., presence of an eye worm and microfilaremia) lead to a diagnosis that is epidemiologically unexpected. In addition, clinicians should be aware that similar clinical presentations might also be increasingly observed in nontropical settings.

\section{Acknowledgments}

We thank all laboratory staff involved in the study for providing technical assistance and Pierre Dorny, Renaud Piarroux, and Anne-Cécile Normand for providing assistance with the molecular techniques.

\section{About the Author}

Mr. Potters is a skills laboratory teacher and a medical laboratory technologist at the national reference laboratory for parasitology at the Institute of Tropical Medicine, Antwerp, Belgium. His research interest is tropical parasitology.

\section{References}

1. Diaz JH. Increasing risks of human dirofilariasis in travelers. J Travel Med. 2015;22:116-23. http://dx.doi.org/10.1111/jtm.12174

2. Pampiglione S, Rivasi F, Angeli G, Boldorini R, Incensati RM, Pastormerlo M, et al. Dirofilariasis due to Dirofilaria repens in Italy, an emergent zoonosis: report of 60 new cases. Histopathology. 2001;38:344-54. http://dx.doi.org/10.1046/ j.1365-2559.2001.01099.x

3. Pietikäinen R, Nordling S, Jokiranta S, Saari S, Heikkinen P, Gardiner C, et al. Dirofilaria repens transmission in southeastern Finland. Parasit Vectors. 2017;10:561. http://dx.doi.org/10.1186/ s13071-017-2499-4 
4. Wong MM. Experimental dirofilariasis in macaques. II. Susceptibility and host responses to Dirofilaria repens of dogs and cats. Am J Trop Med Hyg. 1976;25:88-93. http://dx.doi.org/ 10.4269/ajtmh.1976.25.88

5. MacDougall LT, Magoon CC, Fritsche TR. Dirofilaria repens manifesting as a breast nodule. Diagnostic problems and epidemiologic considerations. Am J Clin Pathol. 1992;97:625-30. http://dx.doi.org/10.1093/ajcp/97.5.625

6. Magnis J, Lorentz S, Guardone L, Grimm F, Magi M, Naucke TJ, et al. Morphometric analyses of canine blood microfilariae isolated by the Knott's test enables Dirofilaria immitis and D. repens species-specific and Acanthocheilonema (syn. Dipetalonema) genus-specific diagnosis. Parasit Vectors. 2013;6:48. http://dx.doi.org/10.1186/1756-3305-6-48

7. Liotta JL, Sandhu GK, Rishniw M, Bowman DD. Differentiation of the microfilariae of Dirofilaria immitis and Dirofilaria repens in stained blood films. J Parasitol. 2013;99:421-5. http://dx.doi.org/10.1645/12-10.1

8. Gioia G, Lecová L, Genchi M, Ferri E, Genchi C, Mortarino M. Highly sensitive multiplex PCR for simultaneous detection and discrimination of Dirofilaria immitis and Dirofilaria repens in canine peripheral blood. Vet Parasitol. 2010;172:160-3. http://dx.doi.org/10.1016/j.vetpar.2010.04.027

9. Latrofa MS, Weigl S, Dantas-Torres F, Annoscia G, Traversa D, Brianti E, et al. A multiplex PCR for the simultaneous detection of species of filarioids infesting dogs. Acta Trop. 2012;122:150-4. http://dx.doi.org/10.1016/j.actatropica.2012.01.006

10. Fontanelli Sulekova L, Gabrielli S, De Angelis M, Milardi GL, Magnani C, Di Marco B, et al. Dirofilaria repens microfilariae from a human node fine-needle aspirate: a case report. BMC Infect Dis. 2016;16:248. http://dx.doi.org/10.1186/s12879-016-1582-3

Address for correspondence: Idzi Potters, Department of Clinical

Sciences, Institute of Tropical Medicine Antwerp, Kronenburgstraat 43/3, 2000 Antwerp, Belgium; email: ipotters@itg.be

\section{Rubella Virus Genotype 1E in Travelers Returning to Japan from Indonesia, 2017}

\author{
Daiki Kanbayashi, Takako Kurata, Yuka Nishino, \\ Fumi Orii, Yuki Takii, Masaru Kinoshita, \\ Toshitake Ohara, Kazushi Motomura, \\ Takahiro Yumisashi
}

Author affiliations: Osaka Institute of Public Health, Osaka, Japan (D. Kanbayashi, T. Kurata, K. Motomura, T. Yumisashi); Osaka Prefectural Government Department of Health and Medical Care, Osaka (Y. Nishino, F. Orii, Y. Takii, M. Kinoshita); Osaka Prefectural Government Ikeda Healthcare Center, Osaka (T. Ohara)

DOI: https://doi.org/10.3201/eid2409.180621
Although rubella is epidemic in Indonesia, the phylogenetic profile of circulating rubella virus strains has not been clarified. In 2017, rubella virus was detected in 2 travelers who returned from Indonesia to Japan. These strains were classified into genotype $1 \mathrm{E}$ lineage 2 , which may be an indigenous strain in Indonesia.

$\mathrm{R}$ ubella is a mild contagious disease caused by the rubella virus, genus Rubivirus, family Togaviridae (1). Fetal death or congenital rubella syndrome (CRS) can occur when infection arises in pregnant women (1). Rubella infections and CRS cases have declined in many countries because of vaccination (2); however, an estimated 110,000 CRS cases occurred globally in 2010, with almost half developing in Southeast Asia because routine immunization programs against rubella virus had scarcely been introduced in these countries at that time $(3,4)$. As of 2016 , of the 11 countries in Southeast Asia, 8 (Bangladesh, Bhutan, Maldives, Myanmar, Nepal, Sri Lanka, Thailand, and Timor-Leste) had introduced routine immunization (5). However, large epidemics still exist in Southeast Asia, mainly in India and Indonesia, which had not introduced routine immunization as of 2016 (5). In addition, CRS cases in Indonesia were the highest worldwide in 2016 (5). Contrarily, only 1 sequence of the virus in Indonesia was registered in GenBank, from a patient who returned to the United States in 2011 (Hendersonville. NC.USA/15.11, accession no. JX477651). Although these rubella-endemic countries greatly affect the efforts of neighboring countries to control the virus, genetic information of epidemic strains in Southeast Asia remains unclear.

In October 2017, a 29-year-old man in Japan experienced a slight fever and sore throat. He had traveled to Jakarta, Indonesia, in late September, 14 days before symptom onset. He was not previously vaccinated against rubella virus. On day 4 after onset, rashes appeared on his body. Testing by real-time reverse transcription PCR did not detect the measles virus genome, but it detected rubella virus genome via throat swab sample collected on day 7 after onset (6). His illness was diagnosed as rubella; we strongly suspected that he acquired the infection in Indonesia, because the incubation period of rubella virus is $\approx 14$ days and Japan has had no domestic rubella epidemic since 2013.

We amplified the E1 protein-coding region genome of the virus and sequenced the molecular window region (739 nt) (7). We classified this rubella strain into genotype $1 \mathrm{E}$ and deposited it into GenBank (RVs/Osaka.JPN/41.17[1E], accession no. LC333396). We generated a phylogenetic tree including 61 strains using the maximum-likelihood method; it revealed that rubella virus can be classified into 5 distinct lineages (L0-L4), as previously described $(7,8)$. 1E-L1 strains are mainly detected in China and Russia. 1E-L2 strains are mainly detected in or imported from Malaysia, China, and Japan. 1E-L3 strains are detected in or 